\title{
Animal Venom Components: New Approaches for Pain Treatment
}

\author{
Ana Cristina N Freitas and Maria Elena de Lima* \\ Departamento de Bioquímica e Imunologia, Brazil \\ *Corresponding author: Maria E de Lima, Departamento de Bioquímica e Imunologia, Belo Horizonte, Minas Gerais, Brazil \\ Submission: 眥 September 09, 2017; Published: 监 November 06, 2017
}

Abbreviations: NSAID: Non-Steroidal Anti-Inflammatory Drugs; FDA: Food and Drug Administration; nAChRs: Nicotinic Acetylcholine Receptors;

ASICs: Acid-Sensing Ion Channel

\section{Introduction}

This comment has the aim to be illustrative, highlighting some examples of venoms that have shown a great potential as analgesics. It is not our goal to write a review of this subject, considering it is not pertinent in a brief text like this.

Nowadays there is a lot of concern and discussion about animal welfare, since the role that animals play in human life is far beyond of being just our pets. Animals are very important as source of food and undoubtedly, they represent great relevance in scientific research. For all of these reasons, it is tremendously necessary to always improve the animal's well-being.

Pain is a symptom of various different disorders and conditions. Therefore, in the last decades, it has been subject of several researches. Unfortunately, not all of the mechanisms of pain signaling are yet very well understood. The type of pain, and consequently it's treatment, may vary and there are still a lot of difficulties for veterinarians, for example, to prescribe the best treatment or even recognize the different patterns on behavior that may indicate that the animal is actually suffering from pain. Therefore, pain is a symptom that may afflict a broad number of animals, which still may not receive the best treatment.

One of the most common classes of analgesic drugs which are used as a potent pain-killers are the opioids. However, besides causing tolerance, addiction and constipation, administration of opioids may induce respiratory depression as a severe side effect [1]. In addition, the use of non-steroidal anti-inflammatory drugs (NSAID), another classic class of analgesics, is very effective for the treatment of pain. However, it also may cause some serious side effects, such as irritation of the gastrointestinal tract and contribution for the development of renal function abnormalities [2]. Therefore, there is an urge for the discovery of new molecules that may be used for the treatment of different types of pain without causing the very well-known undesirable side effects induced by the use of the currently available drugs.
At the moment, there are a great number of animal toxins that are being studied for treatment or research of many different disorders, including pain. The components isolated from animal venoms gained this interest because of their usual high potency and selectivity in which they act on their molecular targets, such as ion channels or receptors [3]. Currently, a large number of pharmaceutical companies are interested in the development of drugs based on toxins. One of the most successful cases, regarding pain treatment, was the development of Ziconotide (PRIALT). Ziconotide is a potent non-opioid analgesic drug, which is a selective blocker of neuronal N-type voltage-sensitive calcium channels. This molecule is a synthetic equivalent of a $\omega$-conopeptide, which may be found and isolated from the venom of the marine snail Conus magus [4]. This analgesic was approved by Food and Drug Administration (FDA) in 2004 and since then it has been used for treatment of severe chronic pain.

A myriad of different toxins and derivatives obtained from various groups of animals have been described as able to relieve pain through activation or blockage of different molecular targets [5]. Among snakes, there are the cobrotoxin and cobratoxin, isolated from the venom of Najanaja atra and Naja kaouthia, respectively, which present high affinity to different subunits of nicotinic acetylcholine receptors (nAChRs) and exert antinociception [6,7]. Also, another example is crotalphine, isolated from the venom of Crotalus durissus terrificus. This toxin induces antinociception through an opioid-like activity without causing some of the typical side effects induced by the use of opioids, such as tolerance or withdrawal symptoms $[8,9]$. Likewise, the neurotoxin hannalgesin, isolated from Ophiophagus Hannah, and the venom of Micrurus lemniscatus also exert antinociception via activation of the opioid pathway $[10,11]$. In addition, toxins isolated from the venom of the black mamba (Dendroaspis polylepis polylepis)causes strong pain relieve by blocking acid-sensing ion channel (ASICs) [12]. 
Spiders represent the group of venomous animals with the greatest number of species, consequently the venom of these animals is a potential source of new molecules with interesting pharmaceutical activity that may generate new drug candidates for pain treatment, among others [13-15]. Toxins isolated from the venom of Thrixopelma pruriens, Ceratogyrus cornuatus and Phrixotrichus auratus constitute very promising molecules since they are reported to inhibit the different subtypes of voltage gated sodium channels (Nav): Nav1.7 and Nav1.8 $[16,17]$. These subtypes of channels are related to pain signaling, since they are selectively expressed in peripheral sensory neurons and contribute for the transmission of the pain signal [18]. In addition, toxins which block voltage gated calcium channels may induce anti-nociception and are found in the venom of Selenocosmia huwena, Grammostola rosea, Agelenopsis aperta and Phoneutria nigriventer [5,13,14,19,20].

There are many other targets and pathways that might be modulated to induce antinociception. For example, some antinociceptive spider toxins induce antinociception by affecting glutamatergic neurotransmission, blocking ASIC channels, activating opioid and cannabinoid pathways, inhibiting P2X3 receptors, among others [5,21-23]. Recently, many toxins from the spider Phoneutria nigriventer have been studied by the group of Gomez [20,24-28] and by our group [15,21-24], which have highlighted the great potential of these molecules as analgesic models.

Besides the toxins obtained from the venom of snakes and spiders, there are still many other anti-nociceptive components present in the venom of various other groups of venomous animals, such as scorpions, centipedes, bees, wasps, ants, cnidarians and others [5]. This means that we have currently available for research a huge number of bioactive molecules, and probably many of them having very high affinity for a specific receptor or channel.

\section{Conclusion}

In conclusion, the analgesic substances, which were already isolated from venomous animals, may induce anti-nociception with high efficiency through activation or blockage of so many different pathways. This means that many of these substances may become a novel class of commercial analgesic drugs, or even serve as a template for the development of such products. In addition, besides becoming novel medicines, these same substances are helping to understand pain signaling itself, since they exert their activity through various different pathways. Furthermore, there are still many other venom components and animals which were never been studied. Therefore, there are still an enormous number of anti-nociceptive substances yet to be discovered and characterized, which makes animal venoms very promising for both, research and biotechnology. Once a time, thanks to the biodiversity that gives us great insights to the drug discovery.

\section{References}

1. Benyamin R, Trescot AM, Datta S, Buenaventura R, Adlaka R, et al. (2008) Opioid complications and side effects. Pain Physician 11(2 Suppl): 105 120.
2. Whelton A, Hamilton CW (1991) Nonsteroidal anti-inflammatory drugs: effects on kidney function. J Clin Pharmacol 31(7): 588-598.

3. Rajendra W, Armugam A, Jeyaseelan K (2004) Toxins in anti-nociception and anti-inflammation. Toxicon 44(1): 1-17.

4. Miljanich GP (2004) Ziconotide: neuronal calcium channel blocker for treating severe chronic pain. Curr Med Chem 11(23): 3029-3040.

5. Gazerani P, Cairns BE (2014) Venom-based biotoxins as potential analgesics. Expert Rev Neurother 14(11): 1261-1274.

6. Chen ZX, Zhang HL, Gu ZL, Chen BW, Han R, et al. (2006) A longform alpha-neurotoxin from cobra venom produces potent opioidindependent analgesia. Acta Pharmacol Sin 27(4): 402-408.

7. Cheng BC, Zhou XP, Zhu Q Gong S, Qin ZH, et al. (2009) Cobratoxin inhibits pain-evoked discharge of neurons in thalamic parafascicular nucleus in rats: involvement of cholinergic and serotonergic systems Toxicon 54(3): 224-232.

8. Konno K, Picolo G, Gutierrez VP, Brigatte P, Zambelli VO, et al. (2008) Crotalphine, a novel potent analgesic peptide from the venom of the South American rattle snake Crotalus durissus terrificus. Peptides 29(8): 1293-1304

9. Picolo GR, Giorgi, Cury Y (2000) Delta-opioid receptors and nitric oxide mediate the analgesic effect of Crotalus durissus terrificus snake venom. Eur J Pharmacol 391(1-2): 55-62.

10. Pu XC, Wong PT, Gopalakrishnakone P (1995) A novel analgesic toxin (hannalgesin) from the venom of king cobra (Ophiophagus hannah) Toxicon 33(11): 1425-1431.

11. Leite dos SGG, Casais e Silva LL, Pereira SMB, Villarreal CF (2012) Antinociceptive properties of Micrurus lemniscatus venom. Toxicon 60(6): 1005-1012.

12. Diochot S, Baron A, Salinas M, Douguet D, Scarzello S, et al. (2012) Black mamba venom peptides target acid-sensing ion channels to abolish pain Nature 490(7421): 552-555.

13. Saez NJ, Senff S, Jensen JE, Er SY, Herzig V, et al. (2010) Spider-venom peptides as therapeutics. Toxins (Basel) 2(12): 2851-2871.

14. Cury Y, Picolo G (2006) Animal toxins as analgesics--an overview. Drug News Perspect 19(7): 381-392.

15. de Lima ME (2015) Phoneutria nigriventer Venom and Toxins: A Review. In: Gopalakrishnakone P, et al. (Eds.), Spider Venoms. Springer Netherlands, p. 1-24.

16. Middleton RE, Warren VA, Kraus RL, Hwang JC, Liu CJ, et al. (2002) Two tarantula peptides inhibit activation of multiple sodium channels. Biochemistry 41(50): 14734-14747.

17. Bosmans F, Rash L, Zhu S, Diochot S, Lazdunski M, et al. (2006) Four novel tarantula toxins as selective modulators of voltage-gated sodium channel subtypes. Mol Pharmacol 69(2): 419-429.

18. Gilchrist J, Bosmans F (2012) Animal toxins can alter the function of Nav1.8 and Nav1.9. Toxins (Basel) 4(8): 620-632.

19. Nebe J, Vanegas H, Neugebauer V, Schaible HG (1997) Omega-agatoxin IVA, a P-type calcium channel antagonist, reduces nociceptive processing in spinal cord neurons with input from the inflamed but not from the normal knee joint--an electrophysiological study in the rat in vivo. Eur J Neurosci 9(10): 2193-2201.

20. Rigo FK, Trevisan G, Rosa F, Dalmolin GD, Otuki MF, et al. (2013) Spider peptide $\mathrm{Ph} \alpha 1 \beta$ induces analgesic effect in a model of cancer pain. Cancer Sci 104(9): 1226-1230.

21. Freitas AC, Pacheco DF, Machado MF, Carmona AK, Duarte ID, et al. (2016) PnPP-19, a spider toxin peptide, induces peripheral antinociception through opioid and cannabinoid receptors and inhibition of neutral endopeptidase. Br J Pharmacol 173(9): 1491-1501.

22. Freitas AC, Silva GC, Pacheco DF, Pimenta AM, Lemos VS, et al. (2017) The synthetic peptide PnPP-19 induces peripheral antinociception via 
activation of NO/cGMP/KATP pathway: Role of eNOS and nNOS. Nitric Oxide 64: 31-38.

23. Freitas AC, da Fonseca PD, Pimenta AM, Duarte ID, de Lima ME, et al. (2016) A spider derived peptide, PnPP-19, induces central antinociception mediated by opioid and cannabinoid systems. J Venom Anim Toxins Incl Trop Dis 22: 34

24.Emerich BL, Ferreira RC, Cordeiro MN, Borges MH, Pimenta AM, et al. (2016) $\delta$-Ctenitoxin-Pn1a, a Peptide from Phoneutria nigriventer Spider Venom, Shows Antinociceptive Effect Involving Opioid and Cannabinoid Systems, in Rats. Toxins (Basel) 8(4): 106.

25.Palhares MR, Silva JF, Rezende MJS, Santos DC, Silva-JCA, et al. (2017) Synergistic antinociceptive effect of a calcium channel blocker and a TRPV1 blocker in an acute pain model in mice. Life Sci 182: 122-128.
26. Rigo FK, Trevisan G, De Prá SD, Cordeiro MN, Borges MH, et al. (2017) The spider toxin Ph $\alpha 1 \beta$ recombinant possesses strong analgesic activity. Toxicon 133: 145-152.

27.da Silva JF, Castro-JCJ, Oliveira SM, Dalmolin GD, Silva CR, et al. (2015) Characterization of the antinociceptive effect of PhTx3-4, a toxin from Phoneutria nigriventer, in models of thermal, chemical and incisional pain in mice. Toxicon 108: 53-61.

28. Diniz DM, de Souza AH, Pereira EM, da Silva JF, Rigo FK, et al. (2014) Effects of the calcium channel blockers Ph $\alpha 1 \beta$ and $\omega$-conotoxin MVIIA on capsaicin and acetic acid-induced visceral nociception in mice. Pharmacol Biochem Behav 126: 97-102. 